\title{
FARMERS' WOODLOTS-A SOURCE OF QUALITY MATERIAL
}

\author{
By J. W. B. Sisam \\ Dominion Forest Service
}

$\mathrm{T}^{\mathrm{T}}$

HE management of farmers' woodlots is only one phase of the programme of forest research which is being undertaken by the Federal Forest Service. Its initiation in Nova Scotia has no special significance except that this is one of the places in Canada where this problem is of importance, and for some years prior to 1928 the Federal Forest Service had received requests from Nova Scotia to initiate forest research work in that province. It may be said that during the period of estab. lishment of the work, and during the subsequent period of re-examination, this Service has received the whole-hearted co-operation and support of the Forest Service of Nova Scotia.

Experimentation with the management of farmers' woodlots as an initial step to introducing the practice of forestry into the woods has much to commend it. Farmers may be said to form the backbone of the country, and if they can be shown that "management for sustained yield" is not merely a myth but an actual business proposition, a long step towards correct management of our forest domain will have been achieved. Furthermore, his forest unit is not in most cases, large, so that it is not beyond the capacity of the farmer to conduct such operations as thinning, release cutting and reproduction cutting. Much of his time, in the winter, is spent in the woods in any event.

During the summer of 1928, a research party from the Federal Forest Service, working in co-operation with the Department of Lands and Mines of Nova Scotia, surveyed, established and measured five sets of permanent sample plots in farmers' woodlots in the Annapolis Valley of Nova Scotia. While these five specific sets of plots were located in Kings and Annapolis counties, it is proposed to establish similar experimental areas in all parts of the province in the near future. Although a small part of the forested area of the mainland of Nova Scotia and most of the Cape Breton Island is still controlled by the Provincial Government, about $76 \%$ of the forested land of Nova Scotia has been placed under private ownership, and thus the forests have been broken up into a large number of small holdings. While the cutting rights on many of these holdings are at present held en bloc by pulp and paper companies, there are still numbers of farmers and small landowners who control their own woodlots. The project under consideration is the thinning of these woodlots to the financial advantage of the owners, and to the subsequent increase in quality and merchantability of the remaining stands. 
The ten plots, located on highways for demonstration purposes and to increase accessibility, were established in 1928 in immature white pine, red pine, balsam-spruce and poplar. In each case a pair of plots was established, one being thinned, and the other left unthinned as control, or as a means of measuring and demonstrating later the exact effect of thinning. Without going into the full technicality of the laying out of these plots, it may be said that each plot is as near an acre in area as possible. Both plots of a given pair must compare as closely as possible in density and site, and the whole area in which the experiment is carried on must not be of less than three acres, and must be representative of type and conditions so that results may be applicable to other localities. The thinning experiment is to be carried on over a period of twenty years, remeasurements and rethinnings being made every four to six years, the period increasing as the stand and experiment become well established. During this period of twenty years, the experimental area is under contract by the owner not to be interfered with in any way.

\section{Economics}

Ordinarily the owner of a small woodlot, in harvesting his crop, cuts, for his market or personal requirements, every tree that is at all merchantable. Thus he leaves a large portion of his woodland with nothing but dying and crooked trees to produce his next crop, and the soil exposed to the drying-out effects of the sun and wind, cutting down its potential value. On the other hand, the remainder of his forest is left in an overstocked condition where intense competition for space reduces annual increment on individual stems. By following a method of thinning, the owner can remove all suppressed, injured and otherwise unhealthy trees, sufficient healthy trees from his lot to supply his needs, and also release the remaining stand from intense competition. He thus keeps his forest soil in a healthy state, weeds his woodlot of undesirable species, gives the better trees a chance to increase normally in size, and eventually he may produce material that will be capable of supplying the demands of a much larger and more critical market. Of course, this latter possibility would require the combined produce of a large number of small woodlots.

In the locality where the plots under consideration were established, that is, in the Annapolis Valley of Nova Scotia, the apple-growing industry provides intensive utilization of small material for barrel manufacture. Scattered everywhere throughout the valley are small mills and cooper shops. Added to these, the local demand for firewood offers a market for thinnings for which there is no other use possible.

Along with this ready demand for thinnings is, as I have said before, the impetus in growth given the remaining trees on the stand, which, by 
selection, are all of the best quality; so that the woodlot owner, while getting financial returns from his thinnings, is, by so treating his forest, also creating a capital which is increasing at a maximum rate of interest.

During the summer of 1932 , the first remeasurement of plots established in 1928 was made, and incidentally two new pairs of plots were located. We now have comparative figures to show the relative growth on thinned and unthinned plots over a four-year period.

As time is limited, I will deal only with two sets of plots-one set in the immature poplar type, and one in the immature pine type.

The first set of plots which we shall consider is in a poplar stand twenty-five years of age. There is much immature and scrubby poplar throughout the valley which is used chiefly for firewood before reaching an otherwise merchantable size. The object of a thinning in such a stand is to endeavour to produce a final crop of the highest quality poplar for manufacturing purposes, while continuing to use the periodic thinnings for the usual market. The choice of poplar as the final crop tree is due to its characteristic dominance in this type, and to the fact that a ready market is always available.

The two plots established were each an acre in size, and one plot was then thinned by an experience method, that is, a tree by tree selection from below made in such a way that, while all trees have room to grow during the time elapsing between thinnings, the crown cover is sufficiently preserved to preclude any great change in the ground cover such as the establishment of weeds and undergrowth. In this first thinning, approximately nine cords of material were taken from the plot.

The relative number of stems on the two plots after thinning were as follows:

$\begin{array}{lr}\text { Control } & 2428 \\ \text { Thinned } & 833\end{array}$

But of the 2428 stems on the control plot, over 2000 were in the 1,2 and 3 -inch classes, and approximately one-half the stems were of other species than poplar. The elimination on the thinned plot of small, suppressed trees, and the elimination of other species than poplar, in order to promote the growth of the latter species accounts for the great discrepancy in total numbers of stems on the plots as shown above.

The following figures show comparatively the number of stems and the volumes of the total stands of both the thinned and control plots. They demonstrate that the great divergence in total number of stems on each plot is greatly offset in total volumes by the fact that the weighted average diameter is much higher in the thinned plot than in the control plot. 


Total stand \begin{tabular}{ccccc} 
& No. of trees & \multicolumn{2}{c}{ Volumes } \\
& Trees & ratio & Cu. ft. & ratio \\
Control plot & 2428 & 9 & 1628 & 4 \\
Thinned plot & 833 & 3 & 1194 & 3
\end{tabular}

While a four-year period is hardly long enough to obtain any very definite results on such an experiment as this, nevertheless the results of the remeasurement during the past season, and the comparison of these figures with the original data, provide some idea of the comparative growth of the two plots.

In comparing the growth in volume on the two plots for the 4-year period 1928-1932, we find that the net increment on the total stand for the thinned plot is 244 cubic feet, while that on the unthinned plot is 238 cubic feet. Thus there is an average annual net increment for the thinned plot of 61 cubic feet, and for the unthinned plot, of 59 cubic feet.

It should be noted that the average annual increment is larger on the thinned plot than on the control plot, though based on approximately one-third as many trees, these latter trees being, however, of a much higher quality.

The difference in mortality on the two stands gives another possibility for comparison. On the thinned plot, a total of 85 trees containing 62 cubic feet of material died during the four-year period, while on the control plot, 445 trees, containing 161 cubic feet, died during the same length of time. Mortality will be reduced to a minimum on the thinned plot, as the experiment progresses and the continued removal of undesired trees increases the health of the remaining stand.

Using a converting factor of $100 \mathrm{cu}$. ft. to the cord, the amount of wood taken from the thinned plot in the second thinning was approximately 4 cords, as compared to 9 cords taken in the first thinning.

As a result of the operation carried on in these plots up to the present time, there is a volume of standing timber on the thinned plot of approximately 12 cords, plus 13 cords of thinnings, making a total yield of 25 cords. In comparison to this there are 19 cords of living material at present on the control plot. As the original stands contained 21 cords and 16 cords respectively, the thinned plot has made a gain in yield of 1 cord of timber for the four-year period over that of the control plot, thus showing a positive result from the experiment.

The two other plots which we shall consider were established in an immature white pine and white spruce stand. This stand originated as an understory, following a temporary white birch and poplar stand. After the initial thinning in 1928, it presented the appearance from the road of a 
dense, almost pure stand of white pine. The thinning favoured the white pine as the final crop tree.

Originally the plot to be thinned and control plot contained 1576 and 1337 trees respectively. A comparison of the two plots with respect to numbers of stems and volume after the first thinning of 11 cords is as follows:

\begin{tabular}{cccc}
\multicolumn{2}{c}{ Thinned Plot } & \multicolumn{2}{c}{ Control Plot } \\
No. trees & Volume & No. trees & Volume \\
& Cu. Ft. & & Cu. Ft. \\
441 & 1292 & 370 & 1292 \\
625 & 1784 & 1337 & 3162
\end{tabular}

Total Stems

It will be seen that in the case of the white pine the volumes for the two plots are equal, but the number of trees in the control plot is less than the number in the thinned plot-which results in the weighted average diameter in the thinned plot being smaller than in the control plot-the opposite condition to that with which we had to deal on the previous plots. This condition was very marked in comparing the two plots before thinning, and the thinning was not sufficient to offset it in the white pine. However, for the comparison of total stems and volumes, this condition has been offset by thinning.

As we are most interested in the comparative growth on the two plots during the four-year period, let us now consider the following figures of increment.

On the thinned plot containing 625 stems before the second thinning, the net increment for the total stand for the four years was 397 cubic feet, while the net increment on the unthinned stand, containing 1337 stems, for the same period was 248 cubic feet. Or for any individual year, the average net increment for the thinned plot was 99 cubic feet, while that for the control plot was 62 cubic feet only, and it must be remembered that this higher increment is being added to the best quality trees on the stand.

Furthermore, the mortality on the thinned plot for the period is less than $10 \%$ of that on the control plot, both in numbers of stems and volume.

\section{MORTALITY}

Thinned Plot

Total No. of stems 21

Volume
$14 \mathrm{cu} . \mathrm{ft}$.

Total No.

$$
\text { Control Plot }
$$

$\begin{array}{cl}\text { of stems } & \text { Volume } \\ 227 & 176 \mathrm{cu} . \mathrm{ft} .\end{array}$

From these figures we may conclude that the thinning of the one plot has made possible the use of trees that would otherwise, in all probability, die and decay.

To the present time, the yield from these two plots is as follows: Standing timber on the thinned plot is approximately 20 cords plus the results of two 
thinnings of approximately 12 cords of timber, or a total yield of 32 cords; while on the control plot, the total stand is 34 cords. Considering that the original stands contained 28 cords and 31 cords respectively, we see that there has been a relative increase in yield of 1 cord on the thinned plot over the control plot for the four years.

We have now considered the results of the experiment, in outline, over the first four years on two of the five sets of plots first established. I may add that the results from the other three sets show much the same comparisons. If these results are so favorable in actual growth on the best trees of the stand, and in reduction of mortality in general, for such a short period, we can surely expect even greater results in future. I think that the figures resulting are proof enough that the experiment is quite worth while.

It may be said that the owners of the woodlots on which we are working are enthusiastic about the experiment, and are carrying on the work into any other timber which they may own. In one case, the property on which the experimental area was located changed hands during the four-year period, and the new owner had started his own thinning experiment in the woodlot oppasite that on which the plots are situated, without any encouragement from outside.

Other forest owners are also taking advantage of the opportunity to learn a method of cutting their woodlots to the greatest advantage. One individual in particular, who owns a very fine stand of red pine, has reaped results already. He was offered $\$ 200.00$ for five acres of his land twenty years ago but did not sell. Soon after our plots were laid out in 1928, he started cutting the trees on his block, imitating our methods as closely as possible. So far, he has had returns of $\$ 2600.00$, and values his five acres as it now stands at $\$ 3000.00$.

The educational value of these plots, situated as they are on main travelled highways, and, moreover, mostly in farmers' woodlots, is very great. We have placed large signs in front of the plots to tell the casual visitor what is being done, and as time passes and the results of thinning become visible to the untrained eye, the wisdom in establishing these experimental areas will become apparent to everyone. 